\title{
Agomelatine in Standard Medical Practice in Depressed Patients: Results of a 1-Year Multicentre Observational Study In France
}

\author{
Philip Gorwood ${ }^{1} \cdot$ Jacques Benichou ${ }^{2} \cdot$ Nicolas Moore $^{3} \cdot$ Marine Wattez $^{4} \cdot$ Marie-Cécile Secouard $^{5} \cdot$ Xavier Desobry $^{5}$. \\ Françoise Picarel-Blanchot ${ }^{4,5}$ (1) $\cdot$ Christian de Bodinat ${ }^{5}$
}

Published online: 29 July 2020

(c) The Author(s) 2020

\begin{abstract}
Background and Objectives Non-interventional studies are a valuable source of evidence that is complementary to traditional randomised, blinded and controlled clinical trials, for evaluating antidepressants in a real-world setting. The aim of the present study was to document the use of agomelatine in current medical practice and evaluate its effectiveness and safety in outpatients prescribed agomelatine to treat their current depressive episode.

Methods This 12-month observational French study included patients initiating agomelatine treatment. The intensity and severity of depression were assessed using the 17-item Hamilton Depression Rating Scale (HAM-D17) total score and the Clinical Global Impression-Severity of Illness (CGI-S) scale. Patients' quality of life and functioning were measured using the Quality of Life in Depression Scale and the Sheehan Disability Scale, respectively. The safety measures included emergent adverse events and biological samplings, with a focus on liver acceptability.

Results A total of 1484 patients ( $70 \%$ of women; $49.6 \pm 15.4$ years of age) were enrolled in the study. Most patients (62.3\%) were treated with agomelatine for at least 6 months and $28.8 \%$ were treated for at least 1 year. Mean HAM-D17 total score and mean CGI-S scores decreased by $13.6 \pm 8.1$ and $2.1 \pm 1.5$ points, respectively, from baseline to last visit on agomelatine. Rates of responders (i.e. with a decrease in HAM-D17 total score by at least 50\%) and remitters (HAM-D total score $<7$ ) at the last visit were $90.7 \%$ and $56.0 \%$, respectively. The mean HAM-D total score decreased after agomelatine withdrawal $(-4.1 \pm 6.7)$ until the last visit. The quality of life and daily functioning of patients improved, while the numbers of days lost and underproductive days decreased over the follow-up period. Safety findings were in accordance with the known information regarding agomelatine.
\end{abstract}

Conclusion In the current medical practice, this study confirms the effectiveness and good tolerability of agomelatine administered for a treatment period in agreement with guideline recommendations.

Trial registration number ISRCTN53570733 on 27 August 2010.

Françoise Picarel-Blanchot

francoise.picarel@fr.netgrs.com

1 Centre Hospitalier Sainte-Anne (GHU Paris Psychiatrie et Neurosciences), INSERM U1266 and Paris-Descartes University, Paris, France

2 Centre Hospitalier Universitaire de Rouen, Unité de Biostatistiques, Rouen, France

3 INSERM CIC1401, Université de Bordeaux, 33076 Bordeaux, France

4 Servier Affaires Médicales, 35 Rue de Verdun, 92284 Suresnes Cedex, France

5 Institut de Recherches Internationales Servier (IRIS), 50 Rue Carnot, 92284 Suresnes Cedex, France

\section{Introduction}

Major depressive disorder (MDD) is the most common psychiatric disorder worldwide, with a lifetime prevalence of approximately $13 \%[1,2]$, and is associated with marked morbidity and premature mortality [3]. In everyday medical practice, only a minority of patients complete the 6 months of treatment considered to be medically necessary to prevent relapses and the development of chronic depression [4-6]. A 12-month follow-up study of approximately 1 million patients initiating antidepressant treatment in France has shown that more than $80 \%$ of patients had a treatment duration of $<6$ months [7]. Increasing the proportion of patients with MDD who receive antidepressant treatment 


\section{Key Points}

We conducted a non-interventional study on a large patient sample representative of the French population of outpatients with major depressive disorder.

The findings confirm, under daily practice conditions, the long-term (1 year) efficacy and good tolerability of agomelatine.

for a duration that complies with current recommendations remains a key challenge.

Of the available licensed treatments for MDD, many have closely similar mechanisms of action. For this reason, the distinct pharmacological properties of agomelatine (agonistic $\mathrm{MT}_{1} / \mathrm{MT}_{2}$ and antagonistic $5-\mathrm{HT}_{2 \mathrm{C}}$ receptor activities) [8] may translate into an original clinical profile compared with other antidepressants. A singular pharmacokinetic profile of a drug with a very short half-life and pharmacodynamic properties allowing a single daily administration would both avoid prolonged adverse effects and facilitate compliance for long-term treatment [9]. It would therefore be relevant to collect real-world data on adherence to agomelatine treatment.

Agomelatine antidepressant efficacy has been demonstrated at daily doses of $25-50 \mathrm{mg}$ in the treatment of the full range of depressive symptoms in patients with moderate to severe MDD [10], with an effect size comparable with that of other currently available compounds [11, 12]. Agomelatine treatment is efficacious over the long-term [13-15]. Other aspects such as well-being, improvement of sleep disorders, daily functioning, and sexual function have also been seen with this compound [14], and have been associated with a high rating of acceptability (i.e. treatment discontinuations due to any cause) according to a recent network meta-analysis [12].

Agomelatine clinical interest was established based on classical evidence predominantly derived from randomised controlled trials (RCTs).

The present observational study was conducted to fulfil the request from the Transparency Committee of the French National Health Technology Assessment Authority (HAS) to document the use of agomelatine in current medical practice. The objective was to investigate agomelatine safety and effectiveness in a real-world setting to complement data obtained in RCTs. The clinical evolution of agomelatinetreated patients, including the severity of depression and rates of relapse, the effects on patients' functioning and quality of life, treatment duration and treatment safety were investigated over the course of 1 year.

\section{Methods}

This was a prospective, observational, national, multicentre cohort study conducted from March 2012 to September 2015. The recruitment of physicians (psychiatrists and general practitioners) was conducted through hospitals, clinics or private practices.

\subsection{Study Participants}

Patients were eligible for enrolment if they met the following entry criteria: male or female patients aged at least 18 years, provided written informed consent, experienced a depressive episode, and patients whose physician decided to begin antidepressive treatment with agomelatine.

At baseline, physicians had to document the characteristics of their patients' current depressive episode by quoting the Diagnostic and Statistical Manual of Mental Disorders, Fourth Edition, Text Revision (DSM-IV-TR) diagnosis criteria corresponding to a major depressive episode.

Patients were not eligible for the study if they participated in another study simultaneously, had to stop a successful ongoing antidepressant treatment, wished to continue another antidepressant treatment in addition to agomelatine, or planned to move during the follow-up period of the study.

This observational study involved patients in current medical practice; in this context, the sponsor did not provide agomelatine treatment. For each patient, the dose and duration of treatment were individually decided by the physician according to recommended depressive status, daily dose, contraindication and precautionary measures mentioned in the summary of product characteristics (SmPC). The decision to enrol a patient in the study, after his/her agreement, was independent from the decision to prescribe agomelatine, and was possible only after the treatment prescription. Furthermore, the study was designed not to affect usual medical practices (e.g. no additional medical visits).

The study was run in accordance with the principles stated in the Declaration of Helsinki (Finland), Good Pharmacoepidemiology Practices [16], Ethical Guidelines for Epidemiological Studies [17] and the applicable regulatory requirements.

\subsection{Clinical Assessments}

The effectiveness of the study medication was measured by the investigator using the 17-Item Hamilton Depression Rating Scale (HAM-D17) total score [18] and the Clinical Global Impression (CGI)-severity of illness (CGI-S) scale [19]. HAM-D17 total scores between 18 and 24 (inclusive) are indicative of a moderate depressive episode (MDE) and scores $>24$ are indicative of a severe MDE. Response was 
defined as a decrease in HAM-D17 total score by at least $50 \%$, remission was defined as HAM-D17 total score $<7$, and relapse was defined as HAM-D17 total score $\geq 16$ after a total score of $\leq 10$.

Patients' quality of life and functioning were measured using the Quality of Life in Depression Scale (QLDS) [20] and the Sheehan Disability Scale (SDS) [21], respectively. The QLDS is a 34-item self-rated questionnaire, scored binomially (0-1). High scores indicate a lower quality of life. For the SDS, the level of impairment is measured for three domains (work, social life, family life) on a scale from 0 ('no impairment') to 10 ('extreme impairment'), thus giving a total score from 0 to 30 .

The tolerability and safety measures included emergent adverse events (EAEs) spontaneously reported by the patient at each visit, biological samplings, physical examination and vital signs (heart rate, blood pressure, weight, body mass index). Liver acceptability was assessed on both biological aspartate aminotransferase (AST) and/or alanine aminotransferase (ALT) levels (liver function test in accordance with the SmPC) and adverse events, if any. For any potentially clinically significant abnormal (PCSA) values, defined as AST and/or ALT $>3 \times$ upper limit of normal (ULN), or any sign of hepatotoxicity, an adverse event was declared. A clinical review of narratives of all patients presenting with PCSA transaminases elevations was made by a Liver Safety Committee composed of four clinical hepatologists and one specialist in internal medicine. For suicidality, completed suicides and suicide attempts were reviewed by an external independent expert.

Cases of suicidality risk (identified using the appropriate section of the Mini International Neuropsychiatric Interview [MINI]) were also collected.

\subsection{Data Analysis}

The planned follow-up duration was 52 weeks, even if the treatment with agomelatine was stopped. Patients no longer attending physician visits were contacted by phone every 3 months to complete a 52-week follow-up duration. For patients who stopped agomelatine treatment at 52 weeks, a safety visit was performed (on-site or by phone) 2 weeks after agomelatine discontinuation.

The sample size calculation was based on the least favourable estimation of incidence rates (50\% for one event) of any events, allowing evaluation of the clinical evolution of depressed patients treated by agomelatine in current medical practice for 1 year (e.g. relapses, hospitalisation, prescription of a new antidepressant, vital status). As a rate of 50\% of completers can be expected in a naturalistic study, the inclusion of 1500 patients allowed an absolute precision of $\pm 3.6 \%$.
For analyses by agomelatine dose, the dose of ' $25 \mathrm{mg}$ ' corresponded to patients who reported an intake of no more than $25 \mathrm{mg} /$ day at each visit, while the dose of ' $25-50 \mathrm{mg}$ ' corresponded to patients who took $50 \mathrm{mg} /$ day at least once, when a dose increase was judged necessary by the investigator, in accordance with the agomelatine SmPC.

Descriptive statistics are presented as mean \pm standard deviation (SD) and median for continuous variables, and as percentages and estimate (standard error) or $95 \%$ confidence interval $(\mathrm{CI})$ of the incidence of event for categorical variables.

Two periods of analysis were considered: the agomelatine treatment period, and the period after agomelatine treatment had ceased. The HAM-D17 and CGI-S (severity of the depressive episode and relapses), QLDS and SDS were described during the agomelatine treatment period and, when available, after agomelatine treatment had ceased. Safety outcomes (including EAEs, liver parameters) were described during the agomelatine treatment period. Incidences of hospitalisations for depressive disorder, suicide attempts and suicides were also reported after agomelatine treatment had ceased. Incidence rates and 95\% CIs were assessed for relapses, hospitalisation for depressive disorder, prescription of a new antidepressant treatment after agomelatine withdrawal, and vital status.

No inferential statistics were performed. Descriptive statistical analyses were performed using $\mathrm{SAS}^{\circledR}$ software version 9.2 (SAS Institute, Cary, NC, USA).

\section{Results}

\subsection{Study Population}

The study involved 134 physicians in France who enrolled a total of 1517 patients initiating agomelatine treatment; 33 patients with a missing date of agomelatine first intake were excluded from the analysis. The agomelatine cohort consisted of 1484 patients. Most patients were recruited by general practitioners (70.9\% of patients), while psychiatrists recruited $29.1 \%$ of patients.

Baseline characteristics are presented in Table 1. Patients were mostly female $(70 \%)$ with a mean age $( \pm$ SD) of $49.6 \pm 15.4$ years $(235$ patients [ $15.8 \%$ ] were $\geq 65$ years of age), and a large majority of patients $(90.6 \%)$ fulfilled the full DSM-IV criteria for MDD diagnosis. Patients presented a mean disease duration of $9.9 \pm 9.7$ years, a current depressive episode duration of 7.6 \pm 18.6 months, and had experienced 1.9 depressive episodes on average (including the current episode). According to the investigators' diagnosis, $17.9 \%$ of patients had psychiatric comorbidities, including anxiety disorders ( $10.2 \%$ of patients), personality disorders (2.0\%), bipolar disorders $(2.0 \%)$, obsessive-compulsive 
Table 1 Patient baseline characteristics $(N=1484)$

\begin{tabular}{|c|c|}
\hline Characteristic & Value \\
\hline Age, years $($ mean $\pm S D)$ & $49.6 \pm 15.4$ \\
\hline Age $>65$ years $(n)$ & 235 \\
\hline Male/female $(\%)$ & $30 / 70$ \\
\hline Body mass index, $\mathrm{kg} / \mathrm{m}^{2}($ mean $\pm \mathrm{SD})$ & $25.0 \pm 5.0$ \\
\hline Time since the first episode, years & $9.9 \pm 9.7$ \\
\hline $\begin{array}{l}\text { Number of depressive episodes, including the pre- } \\
\text { sent episode (mean } \pm \text { SD) }\end{array}$ & $1.9 \pm 1.5$ \\
\hline Duration of current MDE, months (mean \pm SD) & $7.6 \pm 18.6$ \\
\hline Concomitant diseases (\%) & 50.7 \\
\hline HAM-D17 total score (mean \pm SD) & $21.8 \pm 6.4$ \\
\hline QLDS total score [0-34] & $22.3 \pm 7.6$ \\
\hline CGI-S [0-7] (mean \pm SD) & $4.9 \pm 0.7$ \\
\hline SDS total score $[0-30]($ mean \pm SD) & $16.4 \pm 6.0$ \\
\hline SDS work $($ mean \pm SD) & $6.1 \pm 2.5$ \\
\hline SDS social life $($ mean $\pm S D)$ & $6.3 \pm 2.2$ \\
\hline SDS family life (mean \pm SD) & $6.1 \pm 2.2$ \\
\hline
\end{tabular}

$S D$ standard deviation, $M D E$ major depressive episode, HAM-D17 17-Item Hamilton Depression Rating Scale, $Q L D S$ Quality of Life in Depression Scale, CGI-S Clinical Global Impression-Severity of Illness scale, SDS Sheehan Disability Scale

disorders (1.2\%) and psychotic disorders (0.7\%). Based on the MINI suicidality items, $33.4 \%$ of patients had a suicidal risk, most (15.2\%) of whom were at a low level of risk, $8 \%$ at a moderate level of risk and $10.1 \%$ at a severe level of risk.
Half of the patients $(50.7 \%)$ had at least one concomitant disease at inclusion, with hypertension, hypercholesterolaemia and anxiety being the most frequently reported. Based on the HAM-D score, most patients $(1062 / 1484 ; 71.6 \%)$ were moderately $(36.5 \%)$ or severely $(35.1 \%)$ depressed at inclusion. According to the SDS, on average, the patients felt moderately disrupted by symptoms for the three functional domains. In the week preceding the study, a mean of $3.0 \pm 2.8$ days were lost, and $3.6 \pm 2.7$ days were underproductive. Patients felt their quality of life was rather poor (Table 1).

\subsection{Treatment and Follow-Up Duration, and Treatment Discontinuation}

A total of 1213 patients $(81.7 \%)$ were treated with agomelatine $25 \mathrm{mg}$ and $271(18.3 \%)$ were treated with agomelatine $25-50 \mathrm{mg}$ (Table 2). Patients treated with the $25-50 \mathrm{mg}$ dose had more severe disease history in terms of the number of previous depressive episodes, previous hospitalisations and higher suicidal risk (Table 2).

Most patients (62.3\%) were treated with agomelatine for at least 6 months and $28.8 \%$ were treated for at least 1 year; the mean agomelatine treatment was $7.9 \pm 4.5$ months. Patients with uptitrated agomelatine had a mean duration of treatment of $9.4 \pm 3.8$ months (versus $7.6 \pm 4.6$ months for patients who remained on the $25 \mathrm{mg}$ dose).

During the 1-year follow-up, 893 patients $(60.2 \%)$ stopped treatment with agomelatine. The main reason for

Table 2 Baseline characteristics according to dose of agomelatine

\begin{tabular}{lll}
\hline Characteristic & Agomelatine 25 mg fixed dose $(n=1213)$ & $\begin{array}{c}\text { Agomelatine } \\
25-50 \mathrm{mg} \text { dose } \\
(n=271)\end{array}$ \\
\hline Psychotherapy (\%) & & 13.7 \\
Suicidal risk according to investigators (\%) & 11.1 & 27.3 \\
Number of previous suicide attempts (mean \pm SD) & $0.2 \pm 0.8$ & $0.4 \pm 1.1$ \\
Suicidality scale [MINI] (\%) & & 59.0 \\
No risk & 66.1 & 13.7 \\
Low risk & 15.6 & 9.9 \\
Moderate risk & 7.6 & 16.2 \\
High risk & 8.7 & $22.0 \pm 7.1$ \\
HAM-D17 total score (mean \pm SD) & $21.8 \pm 6.3$ & $5.0 \pm 0.7$ \\
CGI-S (mean \pm SD) & $4.8 \pm 0.7$ & $17.9 \pm 5.8$ \\
SDS total score (mean \pm SD) & $16.1 \pm 6.0$ & $24.7 \pm 6.3$ \\
QLDS total score (mean \pm SD) & $21.7 \pm 7.7$ & $2.3 \pm 2.0$ \\
Number of depressive episodes (mean \pm SD) & $1.8 \pm 1.4$ & 44.3 \\
Patients with more than two episodes $(\%)$ & 36.0 & 15.1 \\
Patients previously hospitalised for MDE $(\%)$ & 8.7 & \\
\hline
\end{tabular}

$N$ number of patients in the analysis set, $M I N I$ Mini International Neuropsychiatric Interview, $S D$ standard deviation, $M D E$ major depressive episode, HAM-D17 17-Item Hamilton Depression Rating Scale, QLDS Quality of Life in Depression Scale, CGI-S Clinical Global ImpressionSeverity of Illness scale, SDS Sheehan Disability Scale 
stopping was 'remission' or 'marked improvement' in more than half of the patients (491 patients; $54.9 \%$ of patients who stopped treatment), and other reasons were 'non-medical' (19.2\% of patients who stopped), 'adverse event' (17.2\% of patients who stopped), and 'lack of efficacy' (14.6\% of patients who stopped). A new antidepressant was prescribed to 206 (23.1\%) of the 893 patients who stopped treatment with agomelatine.

During the study period, $70.8 \%$ of patients received at least one concomitant psychotropic treatment, the most common being anxiolytics (34.3\% of patients), antidepressants (20.6\% of patients), hypnotics and sedatives (16.3\%) and antipsychotics (6.2\%).

\subsection{Change in Disease Severity}

The mean HAM-D17 total score decreased by $13.6 \pm 8.1$ from baseline to the last visit under agomelatine treatment (Table 3); $90.7 \%$ of patients were responders (i.e. had a decrease in HAM-D17 total score by at least 50\%) and $56.0 \%$ were remitters (HAM-D-17 total score $<7$ ) at their last visit under agomelatine treatment. During the same period, the mean CGI-S scores decreased by $2.1 \pm 1.5$ points. The mean HAM-D total score still decreased after agomelatine withdrawal $(-4.1 \pm 6.7)$, as well as the mean CGI-S score $(-1.0 \pm 1.5)$ and the mean SDS total score $(-3.3 \pm 6.3)$.

In patients with moderate or severe MDE at baseline, the mean HAM-D17 total score change from baseline to last value under agomelatine treatment was $-15.5 \pm 8.1$ (Table 3), and the mean HAM-D total score after agomelatine withdrawal until the end of study follow-up was $-4.9 \pm 7.2$. This subset of patients included $92.4 \%$ of responders and $50.1 \%$ of remitters. The mean CGI score decreased by $-2.2 \pm 1.5$. Similar findings were observed for patients rated moderately or severely depressed according to the HAM-D17 (Table 3).

\subsection{Relapse}

Relapses occurred in $7.2 \%$ of patients receiving agomelatine treatment during the follow-up period. The frequency of relapses was $8.2 \%$ in the subset of moderately or severely depressed patients.

Hospitalisation as a result of depression was reported in $1.6 \%$ of patients. The estimated incidence of hospitalisations was low in patients treated with the $25 \mathrm{mg}$ fixed dose $(0.9 \%)$ and $4.8 \%$ in the group of patients treated with the $25-50 \mathrm{mg}$ dose. These incidence rates in the moderate or severe subpopulations were similar (2.2\% of hospitalisations, distributed into $1.3 \%$ in the $25 \mathrm{mg}$ dose group and $6.7 \%$ in the $25-50 \mathrm{mg}$ dose group).

\subsection{Quality of Life and Functional Status}

The mean QLDS total score decreased by $12.7 \pm 10.7$ from baseline to the last visit under agomelatine treatment. At the end of the treatment period, the mean score was $9.8 \pm 9.5$, indicating a relatively positive rating of patients regarding their quality of life. Similar results were found in patients with moderate or severe MDE at baseline (Table 4).

SDS total score and subscores decreased from baseline to the last visit, showing an improvement in the functional status of patients in terms of work/daily activities, social life and family life (Table 4). The number of days lost and number of underproductive days decreased on treatment (mean change from baseline to last visit: $-1.8 \pm 2.9$ days and $-2.2 \pm 2.9$ days, respectively). Similar results were obtained in the subset of patients with moderate to severe MDE (Table 4).

\subsection{Safety}

The percentages of patients who reported at least one EAE on treatment was $30.7 \%$ (agomelatine $25 \mathrm{mg}, 28.8 \%$; agomelatine $25-50 \mathrm{mg}, 39.5 \%$ ) [Table 5]. Of note, a similar rate $(32.8 \%)$ was observed in the subset of patients aged aged $\geq 65$ years $(n=235)$. The most frequently affected system organ classes were psychiatric disorders $(8.6 \%)$, infections and infestations $(8.2 \%)$, nervous system disorders (6.9\%) and gastrointestinal disorders (5.7\%).

EAEs were related to treatment in $6.3 \%$ of patients, and led to treatment discontinuation in $8.7 \%$ of patients. Serious EAEs were reported in $8.8 \%$ of patients, with a high incidence in uptitrated patients (agomelatine $25 \mathrm{mg}, 7.1 \%$; agomelatine $25-50 \mathrm{mg}, 16.6 \%$ ) (Table 5). Death occurred in eight patients $(0.5 \%)$, of whom five were $>65$ years of age. No death was considered as treatment-related. Death was related to neoplasm benign, malignant, and unspecified (four patients, $0.3 \%$ ) and infections and infestations (two patients, $0.1 \%$ ), one patient died in a highway accident, and one patient treated with the $25-50 \mathrm{mg}$ dose committed suicide.

EAEs related to sexual dysfunction were reported in three patients $(0.2 \%)$ : erectile dysfunction was reported twice in one patient taking the $25 \mathrm{mg}$ fixed dose, and anorgasmia and ejaculation failure were each reported in one patient taking the $25-50 \mathrm{mg}$ dose. Erectile dysfunction occurred within the first week of treatment, anorgasmia occurred within the second and third months of treatment, and ejaculation failure occurred beyond 3 months of treatment. Anorgasmia was reported with severe intensity. None of these events were serious or led to treatment withdrawal, and none were considered treatment-related by the investigator. All patients with EAEs were recovering or had recovered at the end of the study. 
Table 3 HAM-D17 and CGI-S mean change from baseline to last visit for patients receiving agomelatine

\begin{tabular}{|c|c|c|}
\hline Variable & Agomelatine cohort & $\begin{array}{l}\text { Patients with moder- } \\
\text { ate or severe MDE at } \\
\text { baseline }\end{array}$ \\
\hline$H A M-D 17$ & $(n=1252)$ & $(n=926)$ \\
\hline \multicolumn{3}{|l|}{ Baseline } \\
\hline Mean \pm SD & $22.0 \pm 6.5$ & $24.9 \pm 4.7$ \\
\hline Median & 22.0 & 24.0 \\
\hline \multicolumn{3}{|c|}{ Last visit on agomelatine } \\
\hline Mean \pm SD & $8.4 \pm 7.1$ & $9.4 \pm 7.4$ \\
\hline Median & 7.0 & 8.0 \\
\hline \multicolumn{3}{|c|}{ Change between baseline and last visit on agomelatine } \\
\hline Mean \pm SD & $-13.6 \pm 8.1$ & $-15.5 \pm 8.1$ \\
\hline Median & $\begin{array}{l}-14.0 \\
(n=602)\end{array}$ & $\begin{array}{l}-16.0 \\
(n=437)\end{array}$ \\
\hline \multicolumn{3}{|c|}{ Last visit after agomelatine } \\
\hline Mean \pm SD & $6.2 \pm 6.2$ & $7.1 \pm 6.6$ \\
\hline Median & 4.0 & 5.0 \\
\hline \multicolumn{3}{|c|}{ Change between last visit on agomelatine and last visit on follow-up } \\
\hline Mean \pm SD & $-4.1 \pm 6.7$ & $-4.9 \pm 7.2$ \\
\hline Median & -3.0 & -3.0 \\
\hline$C G I-S$ & $(n=1263)$ & $(n=915)$ \\
\hline \multicolumn{3}{|l|}{ Baseline } \\
\hline Mean \pm SD & $4.9 \pm 0.7$ & $5.1 \pm 0.6$ \\
\hline Median & 5.0 & 5.0 \\
\hline \multicolumn{3}{|c|}{ Last visit on agomelatine } \\
\hline Mean \pm SD & $2.8 \pm 1.5$ & $2.8 \pm 1.5$ \\
\hline Median & 3.0 & 3.0 \\
\hline \multicolumn{3}{|c|}{ Change between baseline and last visit on agomelatine } \\
\hline Mean \pm SD & $-2.1 \pm 1.5$ & $-2.2 \pm 1.5$ \\
\hline \multirow[t]{2}{*}{ Median } & -2.0 & -2.0 \\
\hline & $(n=441)$ & $(n=321)$ \\
\hline \multicolumn{3}{|c|}{ Last visit after agomelatine } \\
\hline Mean \pm SD & $2.3 \pm 1.5$ & $2.4 \pm 1.5$ \\
\hline Median & 2.0 & 2.0 \\
\hline \multicolumn{3}{|c|}{ Change between last visit on agomelatine and last visit on follow-up } \\
\hline Mean \pm SD & $-1.0 \pm 1.5$ & $-1.1 \pm 1.5$ \\
\hline Median & -1.0 & -1.0 \\
\hline
\end{tabular}

$n$ number of patients with an available baseline value and at least one available post-baseline value, $M D E$ major depressive episode, $S D$ standard deviation, HAM-D17 17-Item Hamilton Depression Rating Scale, CGI-S Clinical Global Impression severity of illness

With regard to liver acceptability, 13 patients $(1.1 \%)$ had at least one AST and/or ALT $\geq 3 \times$ ULN, which were divided into four patients with values $>10 \times$ ULN, two patients with values [5-10 $\times$ ULN] and 7 patients with values $[3-5 \times$ ULN] (Table 6 ). There were no cases of PCSA values of AST and/or ALT associated with a total bilirubin increase above $2 \times$ ULN, and no transplantation or hepatic failure was reported. Agomelatine was temporarily interrupted in two patients and discontinued in 10 patients, as recommended by the SmPC in cases of AST and/or ALT increases $\geq 3 \times$ ULN. At the end of the study, seven patients had recovered, four were recovering and two did not recover (alcoholism was reported in both patients).

An event was reported as a serious adverse event (SAE) in seven patients; agomelatine was discontinued in these patients, in line with the SmPC, and all recovered.

- Four patients had an AST and/or ALT increase $>10 \times$ ULN: two cases occurred in the context of a suicide attempt and acute alcoholism leading to 
Table 4 QLDS and SDS mean change from baseline to last visit for patients receiving agomelatine

\begin{tabular}{|c|c|c|}
\hline Variable & Agomelatine cohort & $\begin{array}{l}\text { Patients with moder- } \\
\text { ate or severe MDE at } \\
\text { baseline }\end{array}$ \\
\hline$Q L D S$ & $(n=576)$ & $(n=442)$ \\
\hline \multicolumn{3}{|l|}{ Baseline } \\
\hline Mean \pm SD & $22.5 \pm 7.6$ & $23.6 \pm 7.3$ \\
\hline Median & 24.0 & 25.0 \\
\hline \multicolumn{3}{|l|}{ Last visit on agomelatine } \\
\hline Mean \pm SD & $9.8 \pm 9.5$ & $10.2 \pm 9.6$ \\
\hline Median & 7.0 & 8.0 \\
\hline \multicolumn{3}{|c|}{ Change between baseline and last visit } \\
\hline Mean \pm SD & $-12.7 \pm 10.7$ & $-13.4 \pm 10.9$ \\
\hline Median & -13.0 & -14.0 \\
\hline SDS total score & $(n=1175)$ & $(n=858)$ \\
\hline \multicolumn{3}{|c|}{ Change between baseline and last visit } \\
\hline Mean \pm SD & $-9.2 \pm 7.5$ & $-9.7 \pm 7.7$ \\
\hline Median & -9.0 & -10.0 \\
\hline Work/school & $(n=704)$ & $(n=511)$ \\
\hline \multicolumn{3}{|c|}{ Change between baseline and last visit } \\
\hline Mean \pm SD & $-3.4 \pm 3.0$ & $-3.6 \pm 3.0$ \\
\hline Median & -3.0 & -4.0 \\
\hline Social life & $(n=1175)$ & $(n=858)$ \\
\hline \multicolumn{3}{|c|}{ Change between baseline and last visit } \\
\hline Mean \pm SD & $-3.5 \pm 2.8$ & $-3.7 \pm 2.8$ \\
\hline Median & -4.0 & -4.0 \\
\hline Family life & $(n=1175)$ & $(n=858)$ \\
\hline \multicolumn{3}{|c|}{ Change between baseline and last visit } \\
\hline Mean \pm SD & $-3.4 \pm 2.9$ & $-3.7 \pm 2.9$ \\
\hline Median & -4.0 & -4.0 \\
\hline Number of days lost & $(n=1156)$ & $(n=845)$ \\
\hline \multicolumn{3}{|c|}{ Change between baseline and last visit } \\
\hline Mean \pm SD & $-1.8 \pm 2.9$ & $-2.0 \pm 3.0$ \\
\hline Median & -1.0 & -1.0 \\
\hline Number of underproductive days & $(n=1149)$ & $(n=843)$ \\
\hline \multicolumn{3}{|c|}{ Change between baseline and last visit } \\
\hline Mean \pm SD & $-2.2 \pm 2.9$ & $-2.4 \pm 2.9$ \\
\hline Median & -2.0 & -2.0 \\
\hline
\end{tabular}

$n$ number of patients with an available baseline value and at least one available post-baseline value, $M D E$ major depressive episode, $Q L D S$ Quality of Life in Depression Scale, SDS Sheehan Disability Scale

hospitalisation, and no symptoms were reported for the remaining two patients.

- Two patients had an AST and/or ALT increase [5-10 $\times$ ULN]: one occurred in the context of alcohol intoxication leading to hospitalisation, and the other patient experienced asthenia, headache, and erythematous eruption on her back but no hospitalisation was reported.
- One patient had an AST and/or ALT increase [3-5 $\times$ ULN]: no symptoms were reported but, nevertheless, the investigator considered this increase as serious.

After review by a Liver Safety Committee, five cases of PCSA were considered as 'probably related to agomelatine', one case was considered as 'possibly related', three cases were considered as 'unlikely related' and four cases were considered 'not related' to the treatment. 


\subsection{Suicidality}

Based on the MINI, 45 patients (3.4\%) receiving agomelatine treatment had a severe $(2.0 \%)$ or moderate $(1.6 \%)$ risk of suicide. Events related to suicide/self-injury were reported as SAEs in 23 patients (1.6\%), including emergent suicide attempt and suicidal ideation (13 patients [0.9\%] and 10 patients $[0.7 \%]$, respectively), 10 patients receiving agomelatine $25 \mathrm{mg}$ and 13 patients receiving agomelatine $50 \mathrm{mg}$
(Table 7). The first event occurred during the first month of treatment for 9 of 23 patients (39.1\%).

One patient $(0.1 \%)$ aged 39 years committed suicide during the second month of treatment; this patient had a high risk of suicide according to the MINI suicidality scale, at inclusion. This event was not considered as treatment-related.

Excluding the completed suicide, all events except one (which was a recovering patient) were resolved at the end of

Table 5 Incidence ${ }^{\mathrm{a}}$ of each type of EAE, per dose of agomelatine and in the subset of patients aged $\geq 65$ years

\begin{tabular}{llllc}
\hline Type of adverse events & $\begin{array}{l}\text { Agomelatine cohort } \\
(n=1484)\end{array}$ & $\begin{array}{l}\text { Agomelatine 25 mg } \\
(n=1213)\end{array}$ & $\begin{array}{l}\text { Agomelatine 25-50 mg } \\
(n=271)\end{array}$ & $\begin{array}{l}\text { Patients }>65 \text { years } \\
\text { of age }(n=235)\end{array}$ \\
\hline All & 30.7 & 28.8 & 39.5 & 32.8 \\
Serious EAE & 8.8 & 7.1 & 16.6 & 10.6 \\
EAE related to treatment & 6.3 & 6.4 & 5.5 & 5.1 \\
Withdrawal due to EAE & 8.7 & 9.1 & 7.1 & 9.8 \\
\hline
\end{tabular}

$E A E$ emergent adverse event

${ }^{\text {a }}$ Expressed as a percentage of the number of affected patients to the number of exposed patients

${ }^{\mathrm{b}}$ Including sponsor upgrade

Table 6 Incidence of emergent abnormal AST and/or ALT values $(>3 \times$ ULN), per dose of agomelatine and in the subset of patients aged $\geq 65$ years

\begin{tabular}{lllll}
\hline PCSA value classes & & $\begin{array}{l}\text { Agomelatine cohort } \\
\left(N=1178^{\mathrm{b}}\right)\end{array}$ & $\begin{array}{l}\text { Agomelatine } \\
25 \mathrm{mg}(N=937)\end{array}$ & $\begin{array}{l}\text { Agomelatine } \\
25-50 \mathrm{mg}(n=241)\end{array}$ \\
\hline All & $13(1.1)$ & $8(0.9)$ & $5(2.1)$ & $\begin{array}{l}\text { Patients } \geq 65 \\
\text { years of age } \\
(n=194)\end{array}$ \\
$3-5 \times \mathrm{ULN}$ & $7(0.6)$ & $4(0.4)$ & $3(1.2)$ & $2(1.0)$ \\
$5-10 \times \mathrm{ULN}$ & $2(0.2)$ & $1(0.1)$ & $1(0.4)$ & - \\
$>10 \times \mathrm{ULN}$ & $4(0.3)$ & $3(0.3)$ & $1(0.4)$ & - \\
\hline
\end{tabular}

Data are expressed as $n(\%)$

$N$ number of patients in the analysis set, $n$ number of patients with at least one abnormal value, $\%(\mathrm{n} / \mathrm{N}) \times 100$

$A S T$ aspartate aminotransferase, ALT alanine aminotransferase, ULN upper limit of normal, PCSA potentially clinically significant abnormal, $>3 \times U L N$ emergent abnormal value was defined as a baseline value $\leq 3 \times$ ULN or missing and post-baseline value on treatment period $>3 \times$ ULN

${ }^{\mathrm{a} C}$ Considering the highest post-baseline value

${ }^{b} 79.4 \%$ of patients in the agomelatine cohort with at least one ALT and/or AST value

Table 7 Emergent adverse event related to suicidality

\begin{tabular}{llllll}
\hline Type of adverse events & $\begin{array}{l}\text { Agomelatine cohort } \\
(N=1484)\end{array}$ & $\begin{array}{l}\text { Agomelatine } 25 \mathrm{mg} \\
(N=1213)\end{array}$ & $\begin{array}{l}\text { Agomelatine } \\
25-50 \mathrm{mg}(n=271)\end{array}$ & $\begin{array}{l}\text { Patients } \geq 65 \text { years of } \\
\text { age }(n=235)\end{array}$ & $\begin{array}{l}\text { Patients }<30 \text { years } \\
\text { of age }(N=161)\end{array}$ \\
\hline All & $23(1.6)$ & $10(0.8)$ & $13(4.8)$ & $1(0.4)$ & $3(1.9)$ \\
Suicide attempt & $13(0.9)$ & $6(0.5)$ & $7(2.6)$ & - & $2(1.2)$ \\
Suicidal ideation & $10(0.7)$ & $4(0.3)$ & $6(2.2)$ & $1(0.4)$ & - \\
Committed suicide & $1(0.1)$ & - & $1(0.4)$ & - & - \\
Suicidal behaviour & $1(0.1)$ & - & & - \\
\hline
\end{tabular}

Data are expressed as $n(\%)$

$N$ number of patients in the analysis set, $n$ number of patients with at least one emergent adverse event in any given level 
the study. The frequency of suicidal events was not different in patients aged $<30$ years $(n=161)$ or $\geq 65$ years $(n=235$; $1.9 \%$ and $0.4 \%$, respectively).

\section{Discussion}

The present non-interventional study was aimed at investigating the efficacy and tolerability reported by clinicians prescribing agomelatine in current medical practice in France. The cohort was large and representative of a broad population of depressed patients, including those with multiple comorbidities and drug therapies. In addition, the main sociodemographic characteristics of patients were consistent with those recorded in the IMS-EPPM (Étude Permanente de la Prescription Médicale, a study conducted by IMSHealth; unpublished data) observatory panel of everyday medical practice and prescription by general practitioners in France, therefore suggesting that findings were obtained in a sample of patients who might be more or less representative of the MDD population treated in France.

A diagnosis of MDD according to the DSM-IV criteria was confirmed in a large majority of patients $(90.6 \%)$, most of whom were moderately to severely ill at baseline (72\%), with a rather poor quality of life and a moderate functioning impairment; one-third of patients presented a suicidal risk. Uptitration to $50 \mathrm{mg}$ was required for $18.3 \%$ of patients, a ratio in line with that found during phase III studies of the agomelatine development programme (15-35\%). Characteristics of patients whose treatment was uptitrated to $50 \mathrm{mg}$ included a long disease duration, numerous depressive episodes, and hospitalisations for MDE; these patients had been receiving an antidepressant treatment within the past 12 months and showed high suicidal risk. These characteristics are associated with poorer treatment response and are therefore typical of a population that is medically complex to treat.

The mean HAM-D total score and CGI-S score showed that patients gradually improved along the agomelatine treatment path, even after agomelatine treatment had stopped and until the end of the follow-up period. Rates of responders and remitters according to the HAM-D17 were satisfactory $(91 \%$ and $56 \%$, respectively) at the end of the treatment period. The rate of responders and remitters observed in this study, in current medical practice, were in the same range as those reported in previous clinical trials assessing the efficacy of agomelatine in the long-term (6 months) $[13,22]$, or compared with response and remission rates measured by the Montgomery-Åsberg Depression Rating Scale (MADRS) for antidepressants in clinical trials, such as escitalopram and, more recently, vortioxetine [23, 24]. Our results are also in accordance with the improvement observed in patients treated with agomelatine over a shorter follow-up period (12 weeks) in the large non-interventional Vivaldi study conducted in Germany [25].

Nevertheless, a major residual burden still exists due to insufficiently long treatment durations in everyday medical practice. Patients who are reluctant to and/or do not tolerate antidepressant treatment can rapidly discontinue the treatment [26]. A treatment duration of at least 6 months is recommended to achieve a sufficient improvement of symptoms, and prevent relapse and the chronic evolution of depression [4-6, 24, 27]. However, a 12-month followup study of a large cohort of French patients [7] reported that more than $80 \%$ of patients had a treatment duration of $<6$ months in real-life conditions. By comparison, $62 \%$ of patients in the current study were still treated 6 months after agomelatine initiation, and the mean duration of agomelatine treatment reached approximately 8 months in real-life medical practice conditions in France. Hence, adherence to agomelatine treatment in medical practice observed here is in good agreement with recommendations and is therefore encouraging. This satisfactory adherence could be explained by the low relapse rate in patients receiving agomelatine ( $7 \%$ of patients in the present survey), while approximately $20 \%$ of patients who continue treatment with antidepressants generally experience a relapse [28]. The risk of relapse also depends on the number of residual symptoms [29]. The measured low risk of relapse could be connected to a weak persistency of residual symptoms in patients taking agomelatine, a proposal that would need more controlled protocols. Indeed, agomelatine was shown to improve symptoms such as sleep disorders and anxiety symptoms [14, 30], which are some of the most common residual symptoms [31, 32].

Depressive disorders give rise to serious handicaps and disabilities, which result in the deterioration of a patient's quality of life [33]. The functional status of patients was examined using the SDS [21,34], because the return to a normal level of disabled functioning is as important as a reduction in depressive symptoms [35]. Agomelatine improved depression-related functional disability in treated outpatients. Improvements promoted a balanced functional outcome to a similar degree on all patient functioning domains (work, social life, family life and home responsibilities) associated with a notable decrease in the number of days lost or underproductive days.

Depression and psychiatric comorbid conditions negatively impact quality of life and functioning of patients and there is growing recognition of both types of outcomes in the treatment of depressive disorders $[36,37]$. The improvement of social functioning on agomelatine might contribute to an increased quality of life for patients. At the last visit, the mean QLDS total score reflected a relatively good feeling about patients' quality of life. These findings in everyday medical practice are in line with results reported in agomelatine trials $[15,38-40]$. 
The present study confirms the profile of common emergent adverse effects reported with agomelatine [10,11]. The nature and frequency of adverse events reported here were in accordance with previous knowledge obtained during clinical trials and with the known product information (SmPC). No unexpected EAEs were reported in agomelatine-treated patients. Compared with the group of patients taking the $25 \mathrm{mg}$ fixed dose during the study, there was more frequent reporting of serious EAEs in the group of patients who required uptitration to $50 \mathrm{mg}$. This could not only be due to a lower tolerance of the $50 \mathrm{mg}$ dose but could also be related to the more complex medical history of these patients at baseline.

The good sexual acceptability of agomelatine has been widely demonstrated in short-term studies [41-45] and is confirmed in the present cohort. Over a 1-year period in standard medical practice, three events were reported, of which none were considered related to agomelatine. The absence of deleterious adverse effects on sexual function during agomelatine treatment could be translated into enhanced patient quality of life, and adherence to treatment, therefore potentially favouring recovery from the depressive episode.

As regards to events related to the risk of suicide, the incidence did not differ according to the age of the patients, but was numerically more elevated in the group of patients who required uptitration to $50 \mathrm{mg}$, i.e. who presented with more severe depression characteristics (higher number of previous episodes, higher number of hospitalisations, higher suicidal risk) at the start of treatment.

Regarding hepatic risk, no new information emerged from this observational cohort study. The incidence of AST and/or ALT $\geq 3 \times \mathrm{ULN}$ was low at $0.9 \%$ in patients receiving $25 \mathrm{mg}$ and $2.1 \%$ in patients receiving $25-50 \mathrm{mg}$ (1.1\% for all doses of agomelatine); these increases were isolated and reversible. These observed rates of increases in transaminases in this large cohort were in agreement with those initially reported at the time of agomelatine registration in 2009, and with those from a pooled analysis of 49 agomelatine trials [46]. As with other antidepressants [47], the hepatic adverse events observed with agomelatine consisted mainly of isolated and asymptomatic increases in transaminases, detectable during the first months of treatment, with rare clinical signs. For 1-year follow-up of the agomelatine cohort, there was no Hy's law case (AST or ALT PCSA values + total bilirubin $>2 \times \mathrm{ULN}$ ), no liver transplant, no fulminant hepatitis, no cases of hepatic failure, and no hepatic disorders with fatal outcome. In fact, a study conducted by the French Competent Authority (ANSM) on a cohort of more than 3.8 million subjects has established there was no argument supporting an increased risk of serious hepatic impairment related to the initiation of agomelatine treatment (taken in accordance with the SmPC) compared with selective serotonin reuptake inhibitors [48]. As hepatic transaminase elevation is seen with most antidepressants, their monitoring during, and on discontinuation of, treatment could be seen in general health care for depressed patients [49].

This study has several limitations, including the biases that are typically associated with an observational study design and with the absence of a control group. Various bias factors, apart from the test therapy, could have affected clinical outcomes, such as natural evolution of the disease, adjunctive therapies or observation bias. Nevertheless, the observational nature of the study and the large sample size were adapted to improve the knowledge of the drug in usual practice. Additionally, one limitation of this prospective study was that physicians who agreed to participate in the study, compared with those who never answered or refused, were probably more prone to work in accordance with the recommendations of treatment for depression or the product SmPC. However, in France, the distribution of active physicians according to type of practice matched the distribution according to prescription, therefore it can be expected to be close to real life. In addition, it may be that the population of patients who agreed to enter this prospective study was more compliant, or was more concerned by the disease, and as such might not be fully representative of the depressed population seen in daily practice in France. For these reasons, patients recruited in the present cohort might more easily adhere to the study medication, and it cannot be ruled out that this had inflated the duration of exposure. Of note, in order to address a potential selection bias related to a particular profile of patients prescribed agomelatine, and at the request of the HAS, the study also involved a large cohort involving 7157 depressed patients initiating any antidepressant treatment other than agomelatine and participating only to the baseline visit (data not shown). The comparison of the two cohorts showed only few differences, suggesting that the agomelatine cohort was representative of a broad population of depressed patients treated with antidepressants.

Finally, the rates of missing data could have influenced some results (i.e. QLDS); however, we assume that the number of values analysed in the present cohort might be enough to generate accurate and reliable results. The consistent findings obtained across clinical and observational studies support this hypothesis.

\section{Conclusion}

Our findings confirm, under daily practice conditions, the long-term reported efficacy and good tolerability of agomelatine administered at therapeutically recommended doses according to the SmPC, in a large and mixed patient sample representative of the French population of depressed outpatients. The improvements in symptomatic distress and the 
good tolerability are equally important benefits for patients, and may contribute to a positive perception of agomelatine, likely translate into low relapse rates, and encourage adherence to treatment, the duration of which could be optimised to comply with guideline recommendations.

Author Contributions Christian de Bodinat designed the study and wrote the protocol. Philippe Gorwood supervised the study. Marine Wattez, Marie-Cécile Secouard and Xavier Desobry were in charge of the trial follow-up. Christian de Bodinat and Françoise Picarel-Blanchot managed the literature searches and analyses. Philippe Gorwood, Jacques Benichou and Nicolas Moore wrote the first draft of the manuscript. All authors contributed to and have approved the final version of the manuscript.

\section{Declarations}

Funding This study was sponsored by Servier (Suresnes, France), and Servier employees were involved in the collection and analysis of data.

Ethics approval This study was performed in accordance with the principles stated in the Declaration of Helsinki (Finland), Good Pharmacoepidemiology Practices, Ethical Guidelines for Epidemiological Studies, and the applicable regulatory requirements. The study was approved by the Comité consultatif sur le traitement de l'information en matière de recherche dans le domaine de la santé (CCTIRS; approval number 11026) and the Commission Nationale de l'Informatique et des Libertés (CNIL; approval number 911018).

Informed consent All patients provided their written informed consent.

Conflicts of interest During the last 5 years, Philip Gorwood has received fees for presentations at congresses or participation in scientific boards from Alcediag-Alcen, Angelini, GSK, Janssen, Lundbeck, Otsuka, SAGE and Servier. Over the last 10 years, Jacques Benichou has received fees for participation in scientific boards from Astra Zeneca, Pierre Fabre, IRIS and Research Triangle Institute. Nicolas Moore has received honoraria from the Servier Scientific Committee. Marine Wattez, Marie-Cécile Secouard, Xavier Desobry, Françoise PicarelBlanchot and Christian de Bodinat are employees of Servier.

Open Access This article is licensed under a Creative Commons Attribution-NonCommercial 4.0 International License, which permits any non-commercial use, sharing, adaptation, distribution and reproduction in any medium or format, as long as you give appropriate credit to the original author(s) and the source, provide a link to the Creative Commons licence, and indicate if changes were made. The images or other third party material in this article are included in the article's Creative Commons licence, unless indicated otherwise in a credit line to the material. If material is not included in the article's Creative Commons licence and your intended use is not permitted by statutory regulation or exceeds the permitted use, you will need to obtain permission directly from the copyright holder. To view a copy of this licence, visit http://creativecommons.org/licenses/by-nc/4.0/.

\section{References}

1. Alonso J, Angermeyer MC, Bernert S, Bruffaerts R, Brugha TS, Bryson H, et al. Prevalence of mental disorders in Europe: results from the European Study of the Epidemiology of Mental Disorders (ESEMeD) project. Acta Psychiatr Scand Suppl. 2004;420:21-7.
2. Bromet E, Andrade LH, Hwang I, Sampson NA, Alonso J, de GG et al. Cross-national epidemiology of DSM-IV major depressive episode. BMC Med. 2011;9:90.

3. Chesney E, Goodwin GM, Fazel S. Risks of all-cause and suicide mortality in mental disorders: a meta-review. World Psychiatry. 2014;13:153-60.

4. Davidson JR. Major depressive disorder treatment guidelines in America and Europe. J Clin Psychiatry. 2010;71(Suppl E1):e04.

5. Mitchell AJ. Depressed patients and treatment adherence. Lancet. 2006;367:2041-3.

6. Qaseem A, Snow V, Denberg TD, Forciea MA, Owens DK. Using second-generation antidepressants to treat depressive disorders: a clinical practice guideline from the American College of Physicians. Ann Intern Med. 2008;149:725-33.

7. Fagot JP, Cuerq A, Samson S, Fagot-Campagna A. Cohort of one million patients initiating antidepressant treatment in France: 12-month follow-up. Int J Clin Pract. 2016;70:744-51.

8. Guardiola-Lemaitre B, de BC, Delagrange P, Millan MJ, Munoz C, Mocaer E. Agomelatine: mechanism of action and pharmacological profile in relation to antidepressant properties. Br J Pharmacol. 2014;171:3604-19.

9. Buoli M, Mauri MC, Altamura AC. Pharmacokinetic evaluation of agomelatine for the treatment of generalised anxiety disorder. Expert Opin Drug Metab Toxicol. 2014;10:885-92.

10. de Bodinat C, Guardiola-Lemaitre B, Mocaer E, Renard P, Munoz C, Millan MJ. Agomelatine, the first melatonergic antidepressant: discovery, characterization and development. Nat Rev Drug Discov. 2010;9:628-42.

11. Taylor D, Sparshatt A, Varma S, Olofinjana O. Antidepressant efficacy of agomelatine: meta-analysis of published and unpublished studies. BMJ. 2014;348:g1888.

12. Cipriani A, Furukawa TA, Salanti G, Chaimani A, Atkinson LZ, Ogawa Y, et al. Comparative efficacy and acceptability of 21 antidepressant drugs for the acute treatment of adults with major depressive disorder: a systematic review and network metaanalysis. Lancet. 2018;391:1357-66.

13. Demyttenaere K, Corruble E, Hale A, Quera-Salva MA, PicarelBlanchot F, Kasper S. A pooled analysis of six month comparative efficacy and tolerability in four randomized clinical trials: agomelatine versus escitalopram, fluoxetine, and sertraline. CNS Spectr. 2013;18:163-70.

14. Kennedy SH, Rizvi SJ. Agomelatine in the treatment of major depressive disorder: potential for clinical effectiveness. CNS Drugs. 2010;24:479-99.

15. Kennedy SH, Avedisova A, Belaidi C, Picarel-Blanchot F, de Bodinat C. Sustained efficacy of agomelatine $10 \mathrm{mg}, 25 \mathrm{mg}$, and $25-50 \mathrm{mg}$ on depressive symptoms and functional outcomes in patients with major depressive disorder. A placebocontrolled study over 6 months. Eur Neuropsychopharmacol. 2016;26:378-89.

16. ISPE. Guidelines for good pharmacoepidemiology practices (GPP). Pharmacoepidemiol Drug Saf. 2008;17:200-8.

17. International Ethical Guidelines for Epidemiological Studies. Geneva; CIOMS; 2008.

18. Hamilton M. A rating scale for depression. J Neurol Neurosurg Psychiatry. 1960;23:56-62.

19. Guy W. ECDEU Assessment Manual for Psychopharmacology. US Department of Health, Education and Welfare publication ADM 76-338. Rockville, MD: National Institute of Mental Health; 1976. pp. 217-22.

20. Tuynman-Qua H, de JF, McKenna SP. Quality of life in depression scale (QLDS). Development, reliability, validity, responsiveness and application. Eur Psychiatry. 1997;12:199-202.

21. Sheehan DV, Harnett-Sheehan K, Raj BA. The measurement of disability. Int Clin Psychopharmacol. 1996;11(Suppl 3):89-95. 
22. Corruble E, de BC, Belaidi C, Goodwin GM. Efficacy of agomelatine and escitalopram on depression, subjective sleep and emotional experiences in patients with major depressive disorder: a 24-wk randomized, controlled, double-blind trial. Int J Neuropsychopharmacol. 2013;16:2219-34.

23. Vieta E, Loft H, Florea I. Effectiveness of long-term vortioxetine treatment of patients with major depressive disorder. Eur Neuropsychopharmacol. 2017;27(9):877-84.

24. Wade A, Despiegel N, Heldbo RE. Escitalopram in the long-term treatment of major depressive disorder. Ann Clin Psychiatry. 2006;18:83-9.

25. Laux G. The antidepressant agomelatine in daily practice: results of the non-interventional study VIVALDI. Pharmacopsychiatry. 2012;45:284-91.

26. Masand PS. Tolerability and adherence issues in antidepressant therapy. Clin Ther. 2003;25:2289-304.

27. ANAES. Recommandations pour la pratique clinique. Prise en charge d'un épisode dépressif isolé de l'adulte en ambulatoire. 2002. pp. 1-13.

28. Geddes JR, Carney SM, Davies C, Furukawa TA, Kupfer DJ, Frank E, et al. Relapse prevention with antidepressant drug treatment in depressive disorders: a systematic review. Lancet. 2003;361:653-61.

29. Nierenberg AA, Husain MM, Trivedi MH, Fava M, Warden D, Wisniewski SR, et al. Residual symptoms after remission of major depressive disorder with citalopram and risk of relapse: a STAR*D report. Psychol Med. 2010;40:41-50.

30. Stein DJ, Picarel-Blanchot F, Kennedy SH. Efficacy of the novel antidepressant agomelatine for anxiety symptoms in major depression. Hum Psychopharmacol. 2013;28:151-9.

31. Boulenger JP. Residual symptoms of depression: clinical and theoretical implications. Eur Psychiatry. 2004;19:209-13.

32. Iglesias $\mathrm{C}$, Alonso $\mathrm{M}$. Residual symptoms in depression. Actas Esp Psiquiatr. 2009;37:101-5.

33. Nutt DJ, Kessler RC, Alonso J, Benbow A, Lecrubier Y, Lepine JP, et al. Consensus statement on the benefit to the community of ESEMeD (European Study of the Epidemiology of Mental Disorders) survey data on depression and anxiety. J Clin Psychiatry. 2007;68(Suppl 2):42-8.

34. Sheehan KH, Sheehan DV. Assessing treatment effects in clinical trials with the discan metric of the Sheehan Disability Scale. Int Clin Psychopharmacol. 2008;23:70-83.

35. Greer TL, Kurian BT, Trivedi MH. Defining and measuring functional recovery from depression. CNS Drugs. 2010;24:267-84.

36. Kamenov K, Twomey C, Cabello M, Prina AM, Ayuso-Mateos JL. The efficacy of psychotherapy, pharmacotherapy and their combination on functioning and quality of life in depression: a meta-analysis. Psychol Med. 2017;47:414-25.

37. Sylvia LG, Montana RE, Deckersbach T, Thase ME, Tohen M, Reilly-Harrington N, et al. Poor quality of life and functioning in bipolar disorder. Int J Bipolar Disord. 2017;5:10.
38. Heun R, Ahokas A, Boyer P, Gimenez-Montesinos N, PontesSoares F, Olivier V. The efficacy of agomelatine in elderly patients with recurrent major depressive disorder: a placebo-controlled study. J Clin Psychiatry. 2013;74:587-94.

39. Kennedy SH, Avedisova A, Gimenez-Montesinos N, Belaidi C, de Bodinat C. A placebo-controlled study of three agomelatine dose regimens $(10 \mathrm{mg}, 25 \mathrm{mg}, 25-50 \mathrm{mg}$ ) in patients with major depressive disorder. Eur Neuropsychopharmacol. 2014;24:553-63.

40. Udristoiu T, Dehelean P, Nuss P, Raba V, Picarel-Blanchot F, de BC. Early effect on general interest, and short-term antidepressant efficacy and safety of agomelatine $(25-50 \mathrm{mg} /$ day $)$ and escitalopram (10-20 mg/day) in outpatients with Major Depressive Disorder. A 12-week randomised double-blind comparative study. J Affect Disord. 2016;199:6-12.

41. Kennedy SH. Sexual function in remitted depressed patients following agomelatine and venlafaxine XR treatment. Eur Neuropsychopharmacol. 2005;15:S440.

42. Kennedy SH, Rizvi S, Fulton K, Rasmussen J. A double-blind comparison of sexual functioning, antidepressant efficacy, and tolerability between agomelatine and venlafaxine XR. J Clin Psychopharmacol. 2008;28:329-33.

43. Montejo A, Majadas S, Rizvi SJ, Kennedy SH. The effects of agomelatine on sexual function in depressed patients and healthy volunteers. Hum Psychopharmacol. 2011;26:537-42.

44. Montejo AL, Prieto N, Terleira A, Matias J, Alonso S, Paniagua $\mathrm{G}$ et al. Better sexual acceptability of agomelatine $(25$ and $50 \mathrm{mg}$ ) compared with paroxetine $(20 \mathrm{mg})$ in healthy male volunteers. An 8-week, placebo-controlled study using the PRSEXDQ-SALSEX scale. J Psychopharmacol. 2010;24:111-20.

45. Montejo AL, Deakin JF, Gaillard R, Harmer C, Meyniel F, Jabourian A et al. Better sexual acceptability of agomelatine (25 and $50 \mathrm{mg}$ ) compared to escitalopram (20 mg) in healthy volunteers. A 9-week, placebo-controlled study using the PRSexDQ scale. J Psychopharmacol. 2015;29:1119-28.

46. Perlemuter G, Cacoub P, Valla D, Guyader D, Saba B, Batailler $\mathrm{C}$, et al. Characterisation of agomelatine-induced increase in liver enzymes: frequency and risk factors determined from a pooled analysis of 7605 treated patients. CNS Drugs. 2016;30:877-88.

47. Voican CS, Corruble E, Naveau S, Perlemuter G. Antidepressantinduced liver injury: a review for clinicians. Am J Psychiatry. 2014;171:404-15.

48. Billioti de Gage S, Collin T, Le Tri T, Dray-Spira R, Zureik M. Hépatotoxicité de l'agomélatine (Valdoxan ${ }^{\circledR}$ ) en comparaison des antidépresseurs de la classe des Inhibiteurs sélectifs de la recapture de la sérotonine (ISRS). Revue d'Épidémiologie et de Santé Publique. 2017;65(Suppl. 1):S22.

49. Voican CS, Martin S, Verstuyft C, Corruble E, Perlemuter G, Colle R. Liver function test abnormalities in depressed patients treated with antidepressants: a real-world systematic observational study in psychiatric settings. PLoS One. 2016;11:e0155234. 